\title{
Searching for cryptic species in Erpobdella octoculata (L.) (Hirudinea: Clitellata): discordance between the results of genetic analysis and cross-breeding experiments
}

\author{
Paweł Koperski ${ }^{1,3}$, Rafał Milanowski², Agnieszka Krzyk ${ }^{2}$ \\ ${ }^{1}$ Department of Hydrobiology, University of Warsaw, Banacha 2, 02-097 Warszawa, Poland \\ ${ }^{2}$ Department of Plant Systematics and Geography, University of Warsaw, Aleje Ujazdowskie 4, 00-478 Warszawa, \\ Poland \\ ${ }^{3}$ E-mail: p.t.koperski@uw.edu.pl
}

Key words: COI, cryptic species, discordance, Hirudinea, ITS, molecular taxonomy

\begin{abstract}
The main aim of this study was to reveal reproduction barriers and potentially cryptic radiation within the very common and morphologically variable leech species - Erpobdella octoculata (L., 1758). The differences in reproductive success of the morphological forms were compared experimentally. The data based on the results of field sampling and analysis of ITS and COI sequences is also presented. The results of the analysis of DNA sequences clearly show lack of reproduction barriers between the analysed morphological forms. Subtle differences in DNA sequences between individuals, found with the use of the arbitrary primers method, seem to be related mainly to geographical distance between sub-populations. On the basis of these results, E. octoculata should be treated as one, valid species, in spite of its great morphological variability. However, experimentally confirmed differences in reproductive success of individuals belonging to morphologically divergent forms may be explained by the presence of reproductive barriers between them. Visible incongruity between the results of DNA sequences and the experimental results is not easy to explain this question definitely needs further studies. Different percentages of morphological forms noted in field samples, suggests an adaptive value for divergent colour patterns in different habitats. Such differences may be a result of diverse mortality of individuals differing in colour dwelling on different bottom substrate, caused by predation by benthivorous fish.
\end{abstract}

\section{Contents}

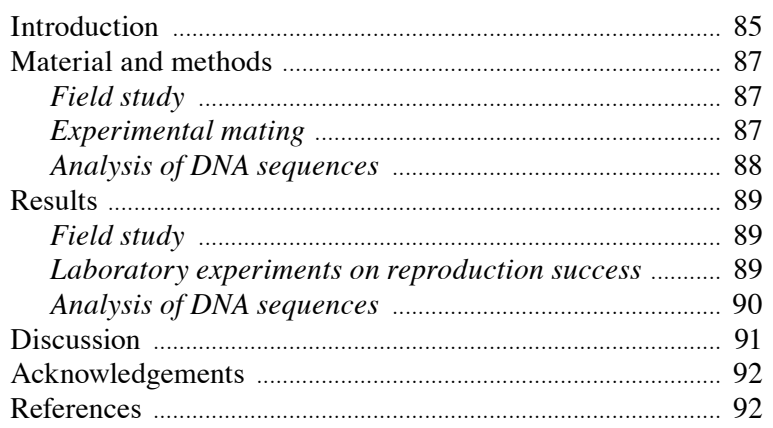

\section{Introduction}

The existence of more species than those currently recognised or estimated is suggested by the abundance of morphologically unrecognised or cryptic species, even in well-known taxa (Barratt et al., 1997). Due to the lack of taxonomically useful morphological characters and widespread dispersal capabilities, many freshwater invertebrates were traditionally believed to constitute single, cosmopolitan species (Suatoni et al., 2006). With the advent of molecular systematics, however, this view has now changed and previously undetected genetic diversity has demonstrated the existence of cryptic species complexes in many aquatic invertebrates (De Meester et al., 2002). The number of cryptic species hidden in various taxonomic groups of freshwater animals is unknown and it seems to be an important element of biological diversity in freshwater environments. The presence of species, which are not distinguished on the basis of morphology but isolated in terms of reproduction, has been studied intensively in recent years because of the recognition of biodiversity protection as a priority for nature conservation.

Bickford et al. (2006) considered two or more species to be 'cryptic' if they are, or have been, classified as a single nominal species because of their at least superficially morphological indistinguishability. Two categories of cryptic species may be distinguished: (i) populations of very similar individuals or even individuals impossible to identify morphologically with strong reproduction barriers between them, (ii) populations previously recognized as a part of a single, highly variable morphologically or ecologically divergent species, sometimes treated as its forms (varietas), in cases where strong reproduction barriers between them have been found. 
Species richness in different taxonomic groups of freshwater invertebrates is still growing as it is demonstrated that numerous common species are in fact cryptic complexes. Examples were presented among molluscs (Korinkova et al., 2006), and many groups of crustaceans (King et al., 1998; Nilssen et al., 2007; Belyaeva and Taylor, 2009) and insects (Williams et al., 2006; Pfenninger et al., 2007; Paredes-Esquivel et al., 2009). Cryptic species were found also among various groups of Clitellata, e.g. Tubificidae (Beauchamp et al., 2001), Lumbriculidae (Gustafsson et al., 2009) and numerous Hirudinea. The number of leech species has been growing in recent years mainly as a result of the acceptance of numerous cases, previously regarded as morphological forms as valid species. It can be illustrated by the cases of the morphological forms of certain common, highly divergent leech species occurring in Europe and North-America such as Glossiphonia complanata (Linnaeus, 1758), Alboglossiphonia heteroclita (Linnaeus, 1761), Erpobdella testacea (Savigny, 1822), Haemopis sanguisuga (Linnaeus, 1758), Piscicola geometra (Linnaeus, 1758), Dina parva Moore 1912, and Erpobdella punctata
(Leidy, 1870), which were finally determined to be valid species (Agapow and Bielecki, 1992; Govedich et al., 1999; Neubert and Nesemann, 1999;Verovnik et al., 1999; Grosser, 2004; Hovingh, 2004; Jueg et al. 2004). Morphological characters, especially the structure of reproductive organs and colouring patterns were mainly used in the past to distinguish between these new species and in the majority of cases specific methods of DNA analysis confirmed the taxonomic arrangements based on morphology (e.g. Utevski and Trontelj, 2004; Hovingh, 2004). Petrauskiene et al. (2009) presented hybrid offspring of interbreeding parents of the genus Hirudo having typical colouration pattern similar to one of the parents and suggested weakness of the reproductive isolation between species.

Erpobdella octoculata (L., 1758) is one of the most common leech species in European freshwaters. It typically dominates the leech assemblages in CentralEuropean lowlands in lake littoral, streams and rivers as well as in urban park ponds (Koperski, 2006). Contrary to other European species of the genus, E. octoculata is an extremely polymorphic species - typically

\begin{tabular}{lcclc}
\hline & \multicolumn{2}{l}{ Running waters } & \multicolumn{2}{l}{ Standing waters } \\
\hline & Stones & Silt and plants & Stones & Silt and plants \\
\hline Very dark (\%) & 5.94 & 58.46 & 0 & 23.35 \\
Dark (\%) & 4.95 & 20.00 & 18.09 & 37.72 \\
Medium dark (\%) & 0 & 9.23 & 21.28 & 29.94 \\
Light (\%) & 24.75 & 9.23 & 59.57 & 8.98 \\
Very light (\%) & 64.36 & 3.08 & 1.06 & 0 \\
NPA (mean with SD) & $81.98 \pm 22.21$ & $21.94 \pm 21.22$ & $63.28 \pm 20.46$ & $33.47 \pm 26.93$ \\
N of individuals & 260 & 65 & 142 & 116 \\
Homogenic group & $\mathrm{A}$ & $\mathrm{B}$ & $\mathrm{A}$ & $\mathrm{B}$ \\
\hline
\end{tabular}

Table 1. Morphological variability of $E$. octoculata expressed as a percentages of morphological forms and values of NPA index (percentage of non-pigmented area on the dorsal side of the body - see methods for details) in different types of freshwater habitats. The results of posthoc comparisons (Tukey's test) presented as a homogenic groups.

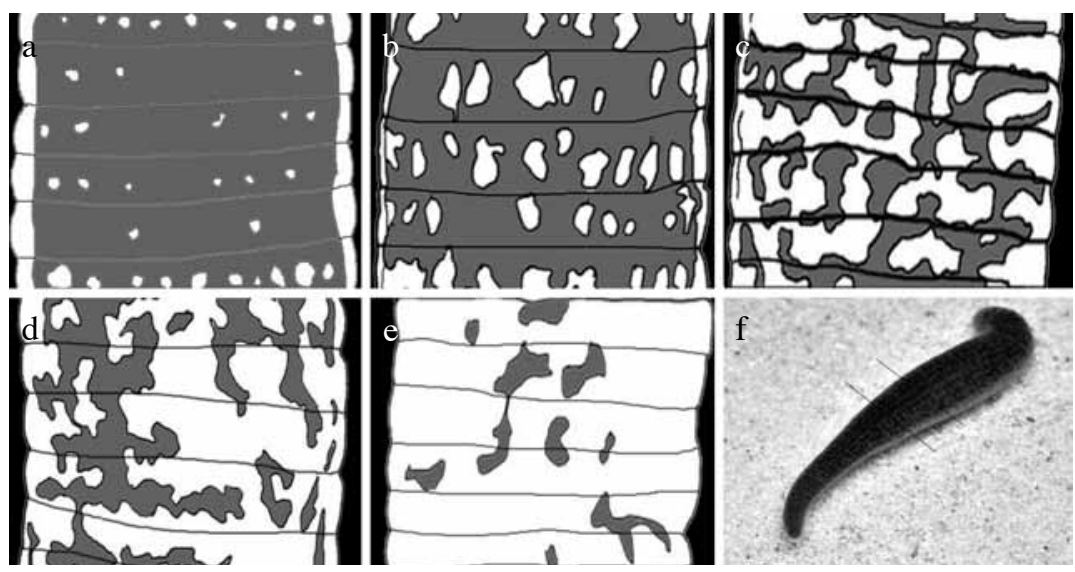

Fig. 1. Morphological forms of Erpobdella octoculata. Schematic drawings of the dorsal side of the individuals' body, presenting colouring patterns (grey - dark pigmented area, white - unpigmented area) on the post-clitelliar region: (a) form 1 - very dark, (b) 2 dark, (c) 3 - medium, (d) 4 - light, (e) 5 - very light, (f) - individual of the form 2 with marked region of the body (somite 14-15) taken into consideration in the analysis. 
at least 4-5 forms or morphotypes, differing in colour, were distinguished. They were traditionally called $f$. vulgaris, atomaria, typica, localis, pallida - all as described by Pawłowski (1936). The rank of these forms in modern taxonomy is not clear - such terms are illegal under International Code of Zoological Nomenclature (1999, article 45.6.4). The most important differences in their colouring patterns are relative area of not-pigmented spots around papillae and background colouring of the body. Individuals of E. octoculata seem to be divergent also in terms of their ecological preferences as well as in terms of their life-history. They were presented by Maltby and Calow (1986) as coexisting semelparous and iteroparous populations.

Partial or complete reproduction barriers between co-habiting forms would explain great variability inside the species. The main aim of this study was to reveal any reproduction barriers and potentially cryptic radiation inside the groups of individuals and populations of E. octoculata. The differences in reproductive success of the morphological forms were compared experimentally. The preliminary results of the study were presented briefly in Koperski et al. (2008). The data presented here are based on the results of field sampling, experimental breeding of selected individuals and analysis of DNA sequences.

\section{Material and methods}

\section{Field study}

A total of 583 individuals of E. octoculata were sampled between 2007 and 2009 in 18 freshwater environments in Poland: rivers, streams, channels, lakes and ponds, differing in terms of their bottom substrate (Table 1). Leeches were sampled manually from stones and with sweep-net from macrophytes and silt. Animals were preserved in $10 \%$ ethyl alcohol and after one hour in $80 \%$ ethyl alcohol. Selected animals were photographed under magnification $c .100 \times$, alive and after preservation. On the basis of the photographic data-base, the sampled individuals were classified into five morphological forms (morphotypes), distinguished mainly on the basis of the area covered by dark pigment on the dorsal surface of the post-clitellar region (measured on somites 14-15) (Fig. 1a-f). These morphological forms are characterised as follows:

1. very dark (Fig. 1a): more than $90 \%$ of the dorsal surface is covered by dark pigment, very rarely the body is completely black on the dorsal side (forma localis - Pawłowski, 1936). Only small spots around papillae arranged in regular rows lack the dark pigment. Ventral surface is coloured dark-grey. The body of an adult specimen is typically large, even to $70 \mathrm{~mm}$ in length - this form is the least frequent of all forms.

2. dark (Fig. 1b): 60-90\% of dorsal surface is covered by dark pigment. Light spots around papillae, arranged in rows have different size but are separated (forma atomaria - Pawłowski, 1936). Ventral surface light (not pigmented). Sometimes the background of the body is red-brownish in colour. The body of adult specimens does not reach $70 \mathrm{~mm}$ in length.

3. medium (Fig. 1c): $35-60 \%$ of dorsal surface is covered by dark pigment. Light, multishaped spots around papillae arranged irregularly are merged (forma typica - Pawłowski, 1936) and typically exceed the borders between annuli. Ventral surface light. The body of adult specimens does not reach $70 \mathrm{~mm}$ in length.

4. light (Fig. 1d): 10-35\% of dorsal surface is covered by dark pigment. Dark, pigmented areas between papillae are joined together (forma pallida - Pawłowski, 1936). Ventral surface light. The body of adult specimens always shorter than $70 \mathrm{~mm}$. Individuals of this form are relatively difficult to distinguish from the type 3 .

5. very light (Fig. 1e): less than $10 \%$ of dorsal surface is covered by dark pigment, sometimes body completely unpigmented (forma pallida - Pawłowski, 1936), pale-ochre coloured in live specimens. Dark spots and relatively large patches, if present, localised mid-dorsally and separated. Sometimes the colour of the body is greenish and darker on the clitellum. Ventral surface light. The body of adult specimens typically large, even to $70 \mathrm{~mm}$.

The differences between different types of environments and between different types of bottom substrates in proportion to particular morphological forms and in mean proportion of pigmented area on the dorsal surface were determined. Statistical significance of the differences in proportions was tested with $\mathrm{Chi}^{2}$ tests, while those in the mean pigment coverage of the body was tested with one-way ANOVA and post-hoc Tukey's test.

\section{Experimental mating}

Morphologically divergent individuals were bred in the laboratory during long-term experimental mating. 
84 parent pairs (168 individuals) of dark, medium and very light forms, collected in lakes Łaśmiady and Wadąg and in the rivers Wisła (Vistula) and Święcek were allowed to reproduce in different combinations for 7 months (June-December). Each pair was separated in polypropylene, cylindrical containers, 0.25 $\mathrm{dm}^{3}$ in volume. A fragment of the wall in each container $\left(20 \mathrm{~cm}^{2}\right)$ was replaced with a plastic net with $1 \mathrm{~mm}$ mesh-size. Each 10 containers were submerged in aquaria filled with circulating, filtrated and aerated water at the temperature of $20^{\circ} \mathrm{C}$ and with constant photoperiod of $16 \mathrm{hrs}$ of light and $8 \mathrm{hrs}$ of darkness. The animals were fed once in two days with live larvae of Chironomidae with regular addition of frozen $\mathrm{Tu}$ bifex, Gammarus and fish meat.

The numbers of cocoons laid and number of hatchlings of each pair were counted. Young individuals were moved to another set of polypropylene containers with the volume of $0.25 \mathrm{dm}^{3}$ with filtered water at the temperature of $20^{\circ} \mathrm{C}$ and with constant photoperiod of $16 \mathrm{hrs}$ of light and $8 \mathrm{hrs}$ of darkness. Young leeches were fed daily with live Enchytraeidae and small Chironomidae. The quantity of offspring of each pair which remained alive after 5 days was recorded. The morphological form of each young individual was determined as soon as it was (15-20 days after hatching). The significance of differences between values of demographic parameters were tested with Wilcoxon's test. The number of cocoons with dead or no embryos was high, as well as mortality, which was high, mainly because of cannibalism.

\section{Analysis of DNA sequences}

The analysis of differences in sequences of two DNA regions was used to search for reproductive barriers between morphologically different individuals.

Mitochondrial sequences of COI (cytochrome oxydase subunit I) of 601 nucleotides in length and ribosomal sequences of the block ITS1/5.8S/ITS2 of 688 nucleotides in length were analysed for 15 individuals of 4 morphological forms (light, medium, dark and very dark) collected in 4 freshwater environments. The sequences of one individual of Erpobdella nigricollis (Brandes, 1900) and one individual of E. vilnensis (Liskiewicz, 1925) were also analysed as outgroups.

To quantify the differences between individuals, differing in morphology and collected in various geographical areas of Poland, their genetic sequences obtained with the AP-PCR method (Arbitrary Primers PCR) were analysed. This group of methods has been commonly used in analysis of intra-population genetic variability of different aquatic invertebrates (e.g. Chambers et al., 1998; Zhou et al., 2005). Polymorphism in 24 primers constructed on the basis of primers presented for Macrobdella decora (Say, 1824) was tested. Totally 24 individuals of 4 morphological forms (light, medium, dark and very dark) collected in 5 freshwater environments (lake Wadąg and the rivers Wieprz near Zwierzyniec, Odra near Kostrzyń, Wisła in Warsaw and Święcek near Drygały) were analysed. Geographical distance between those environments ranged between $100 \mathrm{~km}$ (distance from Wadąg to Święcek) to $700 \mathrm{~km}$ (distance from Odra to Wieprz) (Fig. 2).

The total DNA was isolated from a piece of muscle tissue (approx. $50 \mathrm{mg}$ ) by using the DNeasy Kit (Qiagen, Hilden, Germany) in accordance with the manufacturer's protocol. The exact DNA concentration was measured for each probe using a NanoDrop spectrophotometer (NanoDrop, Wilmington, USA).

The primer pair LCO1490 (GGTCAACAAATCATAAAGATATTGG) and HCO2198 (TAAACTTCAGGGTGACCAAAAAATCA) was used to amplify a fragment of the COI gene; details of the PCR amplification are provided in Hebert et al. (2003).

The second primer pair N-nc18S10 (AGGAGAAGTCGTAACAAG) and C26A (GTTTCTTTTC-

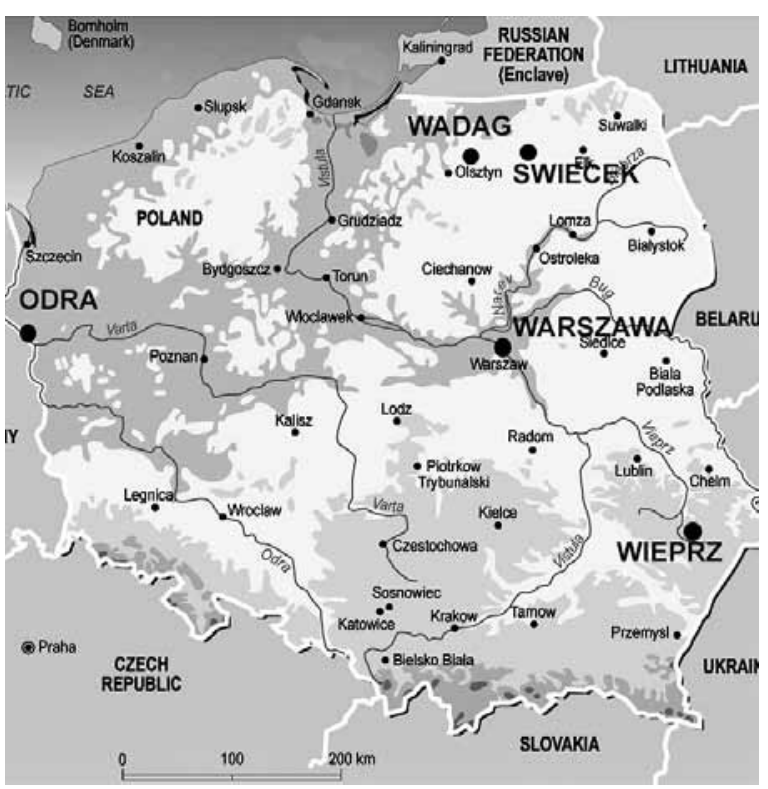

Fig. 2. Map of Poland with the marked sites (black circles) where individuals were sampled from for analysis of genetic similarities with AP-PCR method. 
CTCCGCT) was used to amplify the entire ITS1-5.8SITS2 region (Wen and Zimmer, 1996). A $25 \mu 1$ reaction mixture contained $0.5 \mathrm{U}$ Taq polymerase (Qiagen), $0.2 \mathrm{mM}$ dNTPs, $2.5 \mathrm{mM} \mathrm{MgCl} 2,5$ pmol each primer, reaction buffer (Qiagen) and $20 \mathrm{ng}$ DNA. The PCR protocol consisted of 5 min of denaturation at $94^{\circ} \mathrm{C}$, followed by 35 cycles comprising $1 \mathrm{~min}$ at $94^{\circ} \mathrm{C}$, $1 \mathrm{~min}$ at $52^{\circ} \mathrm{C}$ and $1 \mathrm{~min}$ at $72^{\circ} \mathrm{C}$. The final extension step was performed for $7 \mathrm{~min}$ at $72^{\circ} \mathrm{C}$. Each PCR product was electrophoresed in a $1.5 \%$ agarose gel, stained with ethidium bromide, then excised and purified using a QIAEXII Gel Extraction Kit (Qiagen). PCR products were sequenced from both strands by cycle sequencing using BigDye Terminator Cycle Sequencing Ready Reaction Kit (Applied Biosystems, Foster City, CA, USA). The readings from ABI Prism 3730 DNA sequenator, after removal of primer sequences, were assembled into contigs by the SeqMan program of the Lasergene package (DnaStar, Madison, WI, USA) and checked manually for consistency.

In total 24 primers designed for amplification of 12 microsatellite loci in Macrobdella decora (Budinoff et al., 2004) were tested in Arbitrarily Primers PCR. A $25 \mu \mathrm{l}$ reaction mixture contained $0.5 \mathrm{U}$ Taq polymerase (Qiagen), $0.2 \mathrm{mM}$ dNTPs, $4 \mathrm{mM} \mathrm{MgCl} 2$, reaction buffer (Qiagen), 20 ng DNA and 10 pmol single primer. The PCR protocol (Welsh and McClelland, 1991; modified) consisted of $5 \mathrm{~min}$ of denaturation at $94^{\circ} \mathrm{C}$, followed by 2 low stringency cycles comprising $2 \mathrm{~min}$ at $94^{\circ} \mathrm{C}, 5 \mathrm{~min}$ at $40^{\circ} \mathrm{C}$ and $2 \mathrm{~min}$ at $72^{\circ} \mathrm{C}$, then by 35 high stringency cycles comprising $1 \mathrm{~min}$ at $94^{\circ} \mathrm{C}, 1$ $\min$ at $40^{\circ} \mathrm{C}$ and $2 \mathrm{~min}$ at $72^{\circ} \mathrm{C}$. The final extension step was performed for $7 \mathrm{~min}$ at $72^{\circ} \mathrm{C}$. AP-PCR products were separated in $2 \%$ agarose gel, stained with ethidium bromide, photographed under UV light and analysed.

Genetic similarity between individuals was compared on the basis of AP-PCR products. After removing of all non-informative products (the ones that are present or absent in all individuals) a data-base of 97 products from 9 loci for 24 individuals was created. To calculate genetic similarity between individuals numerical values 0,1 or 2 were assigned. Value 2 was assigned for the presence of pair of bars in individuals (homozygotic), the lack of any bar of the pair was denoted as value 0 (homozygotic) and the presence of only one bar of the pair (heterozygotic) denoted as 1 . Genetic similarity between individuals was determined with UPGMA (Statistica 6) and results were presented as a genetic distance biplot of Multidimentional Scaling based on the UPGMA matrix of simi- larity. The regression coefficient for the relation of the geographical distance between sampling sites and the genetic distance was calculated with Microsoft Office Excel 7.0 software. The genetic distance between groups of individuals (within particular morphological forms and environments as well as between forms and environments) was tested with T test (Statistix 9).

\section{Results}

\section{Field study}

The proportions of morphological forms of leeches sampled from different types of bottom substrate were significantly different. Light and very light individuals dominated on stone bottom, while dark and very dark individuals were more frequent among silt and submerged plants. These differences were more significant in flowing waters than in lakes. The proportions of morphological forms on the stone bottom were significantly different from the silt/plant bottom $\left(\mathrm{Chi}^{2}\right.$ test, $\mathrm{p}<0.01$ ) (Table 1). Mean area of the individuals' dorsal surface of the body covered by the dark pigment was different in four types of environments when tested with ANOVA and post-hoc Tukey's test $(\mathrm{p}=0.05)$ (running waters-stone bottom and standing watersstone bottom - as homogenous group A and running waters-silt/plant bottom and standing waters-silt/plant bottom as homogenous group B).

\section{Laboratory experiments on reproduction success}

As a result of experimental mating of 84 pairs, 492 cocoons were laid from which 2039 offspring hatched. Because of high mortality in first few days after hatching, 1193 individuals (58.5\%) remained alive after 5 days and only 210 individuals (10.3\%) remained alive to the moment when the determination of the morphological form was possible (15-20 days). 10 pairs of these individuals selectively chosen for mating produced 16 offspring (generation F2). The colour pattern of the offspring was not strictly determined by that of their parents - ca. $17 \%$ of the offspring belonged to a different morphological form than both identical parents, and $3 \%$ of them were highly different from the parents (Table 2).

The reproduction success differed between parental pairs belonging to different morphological forms (Table 3). It was significantly higher for morphologically identical parents than that of parents differing in 
morphology when measured by the mean number of cocoons, mean number of offspring hatched and mean number of offspring which survived after 5 days per pair (Wilcoxon's test, $\mathrm{p}<0.01$ ) but not when measured by mean number of offspring per cocoon (Fig. 3). Higher reproductive success of morphologically similar parents suggests the existence of weak reproductive barriers between groups of individuals.

\section{Analysis of DNA sequences}

If there were reproductive barriers between morphological forms, we would expect these to be reflected in fixed differences between these sequences. No repeatable differences in COI and ITS sequences between morphological forms of E. octoculata were found. The lack of polymorphism in these regions clearly shows that no reproductive barriers between morphological forms exist. The results of the analysis of genetic similarity with AP-PCR suggest that diversity is strongly related to geographical distance among populations: individuals collected in the same water body are more similar one to another than to individuals collected in other water bodies (Fig. 4). Individuals most similar in terms of AP-PCR analysis were collected at the nearest sampling sites: the Wadąg lake, Święcek and Wisła

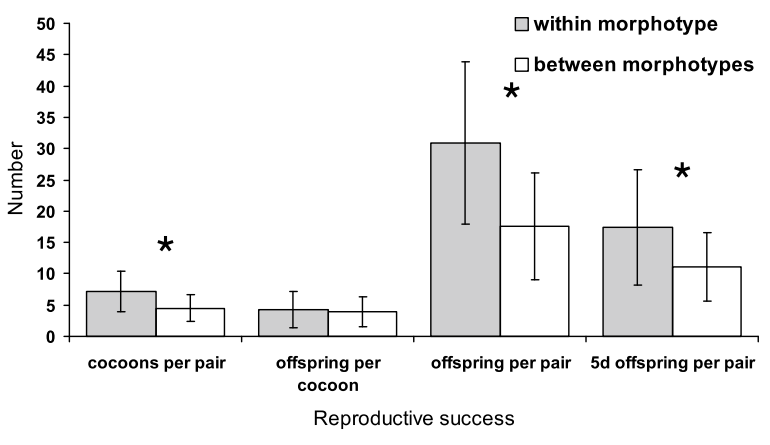

Fig. 3. Reproduction success of morphologically similar and morphologically different parent pairs of E. octoculata expressed as different demographic parameters with SD. * denotes significant difference for 'within forms' vs 'between forms' comparison (Wilcoxon's test).

rivers. Geographical distance, however, does not explain all differences in mean genetic similarity between individuals collected in compared water-bodies - the best fit regression explaining the relation between geographical distance and UPGMA genetic similarity is described by the exponential equation:

$\mathrm{y}=0.1385 \mathrm{x}^{0.4066}$ (with relatively weak value of regression coefficient $R^{2}=0.4012$ )

\begin{tabular}{lllllll}
\hline Parents' morphology & \multicolumn{7}{l}{ Offspring morphology $(\%)$} & & \\
\hline & Very dark & Dark & Medium & Light & Very light & $\mathrm{N}$ \\
\hline Very dark/very dark & 57.58 & 33.33 & 6.06 & 3.03 & 0 & 12 \\
Dark/dark & 3.57 & 71.43 & 17.86 & 7.14 & 0 & 9 \\
Medium/medium & 0 & 15.79 & 63.16 & 21.05 & 0 & 6 \\
Very light/very light & 0 & 2.22 & 6.66 & 35.56 & 55.56 & 15 \\
Very dark/very light & 7.14 & 25.00 & 53.66 & 10.71 & 3.57 & 13 \\
Very dark/medium & 22.22 & 66.67 & 11.11 & 0 & 0 & 4 \\
Dark/light & 0 & 35.42 & 31.25 & 31.25 & 2.08 & 25 \\
\hline
\end{tabular}

Table 2. Percentages of morphological forms in offspring of morphologically similar and morphologically different parents. The number of parental pairs added.

Parents' morphology Reproduction success (individuals per pair)

\begin{tabular}{llll}
\hline & Mean & Median & $\mathrm{N}$ \\
\hline Very dark/very dark & 2.75 & 2.75 & 12 \\
Dark/dark & 3.11 & 4.00 & 9 \\
Medium/medium & 3.17 & 4.05 & 6 \\
Very light/very light & 3.00 & 3.00 & 15 \\
Very dark/very light & 2.11 & 2.52 & 13 \\
Very dark/medium & 2.20 & 2.09 & 4 \\
Dark/light & 1.97 & 2.03 & 25 \\
\hline
\end{tabular}

Table 3. Reproduction success of parent pairs E. octoculata differed in terms of morphology expressed as the number of offspring per pair with SD and median values. The number of parental pairs added. 


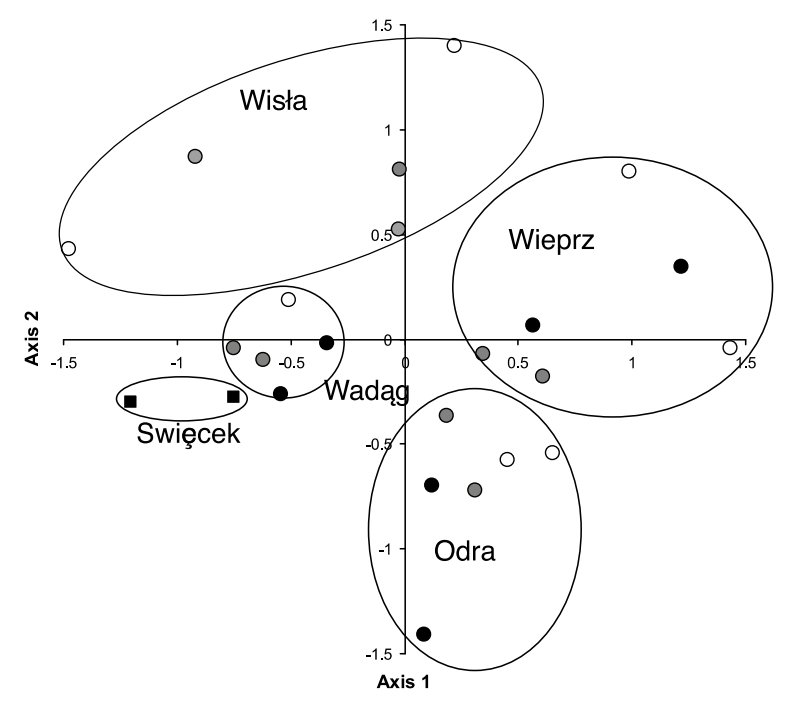

Fig. 4. Biplot of non-hybrid MDS presenting genetic distance (AP-PCR method) between individuals of E. octoculata differed in terms of morphology (empty circles - light form, grey circles - medium form, black circles - dark form, black squares - very dark form) sampled in various environments (marked by ovals).

where $\mathrm{x}$ is geographical distance between sampling sites (in $\mathrm{km}$ ) and y is UPGMA similarity between a pair of individuals.

It is clearly visible that genetic similarity between individuals is not related to their classification into 5 morphological forms. The genetic distance between individuals compared within particular environments was significantly lower than between those compared between environments at $\mathrm{p}<0.0001$ (Table 4). Contrary to that, genetic distance between individuals compared within particular morphological forms did not differ from those compared between forms. Coefficient of variance calculated for values of genetic distance between individuals compared within particular environments was 5.6 times higher than for those compared between environments, which might be explained by the hypothesis that individuals collected in certain environments (e.g. in the Wisła river) are much more genetically diverse than in the other (e.g. in lake Wadąg).

\section{Discussion}

Certain new species have been found in recent years as genetically separated groups of individuals inside former species (complexes) of leeches (e.g. Govedich et al., 1999; Trontelj and Sket, 2000; Hovingh, 2004; Utevsky and Trontelj, 2005) and other common freshwater invertebrates (e.g. Korinkova et al., 2006; Gustafsson et al., 2009) and then confirmed with the results of COI and ITS analysis. The results of the analysis of DNA sequences presented in our study clearly suggest the lack of reproductive barriers between the analysed morphological forms. On the basis of these results, Erpobdella octoculata should be treated as one, valid species, in spite of its great morphological variability. However, these conclusions do not necessarily imply that there are no cryptic species in this taxon over the entire range. The presence of differences in DNA sequences between individuals, found with the use of the AP-PCR method, seems to be related to geographical distance between sub-populations. However, experimentally confirmed diversified reproductive success of individuals belonging to different morphological forms seems to show the presence of weak reproductive barriers between them. The rise of isolated groups of individuals divergent in

\begin{tabular}{|c|c|c|c|c|c|}
\hline Groups of individuals & Distance to compare & Mean & $\mathrm{CV}$ & $\mathrm{p}$ & $\mathrm{N}$ \\
\hline Light & & $1.59 \pm 0.91$ & 0.52 & & 9 \\
\hline Medium & & $0.95 \pm 0.50$ & 0.26 & & 7 \\
\hline \multirow[t]{3}{*}{ Dark and very dark } & & $1.28 \pm 0.59$ & 0.28 & & 8 \\
\hline & within forms & $1.32 \pm 0.77$ & $0.45\}$ & \multirow{2}{*}{0.46} & \\
\hline & between forms & $1.37 \pm 0.85$ & $0.52\}$ & & \\
\hline Wisła & & $1.17 \pm 0.53$ & 0.24 & & 5 \\
\hline Wieprz & & $0.80 \pm 0.32$ & 0.13 & & 6 \\
\hline Odra & & $0.59 \pm 0.28$ & 0.14 & & 6 \\
\hline \multirow[t]{3}{*}{ Wadąg and Święcek } & & $0.34 \pm 0.09$ & 0.03 & & 7 \\
\hline & within environments & $0.72 \pm 0.43$ & $0.68\}$ & \multirow{2}{*}{0.0001} & \\
\hline & between environments & $1.55 \pm 0.70$ & $0.12\}$ & & \\
\hline
\end{tabular}

Table 4. Mean genetic distance (APPCR method) between groups of individuals differed in terms of morphology and sampled in various environments with SD and coefficient of variance for these groups. Result of comparisons between the genetic distance of analysed groups of individuals with T-test are also added as $\mathrm{p}$ values. 
reproductive success and, consequently, new species inside group of co-habiting individuals (or the sympatric speciation) has been supported under specific circumstances (Munday et al., 2004; Barluenga et al., 2006a, b; Schliewen et al., 2006). Sympatric speciation has not been studied in leeches.

There is a visible incongruity between the above results of DNA sequences and the results of experimental study, which is not easy to explain. Results of experimental breeding could be recognized as an effect of 'assortative mating' similar to those described in other aquatic invertebrates (Hull, 1996; Hermann et $a l ., 2009)$. Presented incongruity can also be an effect of impaired reproduction of individuals collected in particular water body, as a result of their disease or weakness. This question definitely needs further studies. It must be emphasized that breeding of E. octoculata in laboratory is difficult and laborious, and these animals reproduce only once a year (those collected in the field as well as those hatched in laboratory), which makes the experimental procedures highly time-consuming.

The results of preliminary experiments on mating of E. octoculata (Koperski, unpublished data) show the lack of any differences in colour pattern of offspring when parents bred on the stone bottom differing in colour (white, black and brown). The different percentage of morphological forms recorded in field samples suggests an adaptive value of divergent colour patterns in different habitats. Such differences may be a result of diverse mortality of individuals differing in colour dwelling on different bottom substrates. The pressure of visual predators like benthivorous fish may be one of the most important factors determining such mortality. The behavioural defence of erpobdellid leeches induced by the presence of freshwater fish was found in experiments by Mr Paweł Prus (Koperski, 2002). It must be added that E. octoculata was found to be a dominant species especially in environments inhabited by benthivorous fish (Koperski, 2006), which suggests a great role of induced, anti-predator defence of this species.

Numerous scientists highlight the study of cryptic species as extremely important in global biodiversity research (Bickford et al., 2006; Cook et al., 2008). The presented results seem to constitute a rarely presented example of genetic uniformity among widely occurring species, highly variable in terms of ecology and morphology. The case of Erpobdella octoculata is an exception when compared with other common, widely distributed and morphologically varia- ble, old-established complexes of European leech species as Erpobdella testacea (one former species divided into 3 species), Glossiphonia complanata (4 species), Glossiphonia (at presence Alboglossiphonia) heteroclita (3 species), Piscicola geometra (ca. 10 species) or Haemopis sanguisuga (2 species) (Grosser - Egel Europas). It stands in opposition especially with the results of Govedich et al. $(1998,1999)$ and Hovingh (2004) concerning North-American erpobdellid species, describing, on the basis of morphology and genetic analysis, a few new species and genera.

\section{Acknowledgements}

This study was financially supported by the grant no 4201/P01/ 2007/32 by Ministry of Science and Higher Education of Republic of Poland. Anonymous reviewers are acknowledged for helpful comments and valuable suggestions.

\section{References}

Agapow L, Bielecki A. 1992. A systematic study on the complex species Erpobdella testacea (Savigny 1820) (Hirudinea Erpobdellidae). Genus 3: 185-199.

Barratt EM, Deaville R, Burland TM, Bruford MW, Jones G, Racey PA, Wayne RK. 1997. DNA answers the call for pipistrelle bat species. Nature 387: 138-139.

Beauchamp KA, Kathman RD, McDowell TS, Hedrick RP. 2001. Molecular Phylogeny of Tubificid Oligochaetes with Special Emphasis on Tubifex tubifex (Tubificidae). Molecular Phylogenetics and Evolution 19: 216-224.

Belyaeva M, Taylor DJ. 2009. Cryptic species within the Chydorus sphaericus species complex (Crustacea: Cladocera) revealed by molecular markers and sexual stage morphology Molecular Phylogenetics and Evolution 50: 534-546.

Barluenga M, Stölting KN, Salzburger W, Muschick M, Meyer A. 2006a. Sympatric speciation in Nicaraguan crater lake cichlid fish. Nature 439: 719-723.

Barluenga M, Stölting KN, Salzburger W, Muschick M, Meyer A. 2006b. Replying to: Schliewen et al. Nature 444: E13, doi:10.1038/nature05420.

Bickford D, Lohman DJ, Sodhi NS, Ng PKL, Meier R, Winker K, Ingram KK, Das I. 2006. Cryptic species as a window on diversity and conservation. Trends in Ecology and Evolution 22: 148-155.

Budinoff RB, Siddall AM, Siddall ME. 2004. Twelve variable microsatellite loci for the North American medicinal leech, Macrobdella decora. Molecular Ecology Notes 4: 491-493.

Chambers RJ, McQuaid CD, Kirby R. 1998. The use of randomly amplified polymorphic DNA to analyze the genetic diversity, the systematic relationships and the evolution of intertidal limpets, Siphonaria spp. (Pulmonata: Gastropoda), with different reproductive modes. Journal of Experimental Marine Biology and Ecology 227: 49-66. 
Cook BD, Page TJ, Hughes JM. 2008. Importance of cryptic species for identifying representative'units of biodiversity for freshwater conservation. Biological Conservation 141: 28212831.

De Meester L, Gomez A, Okamura B, Schwenk K. 2002. The Monopolization hypothesis and the dispersal-gene flow paradox in aquatic organisms. Acta Oecologica 23: 121-135.

Govedich FR, Blinn DW, Keim P, Davies RW. 1998. Phylogenetic relationships of three genera of Erpobdellidae (Hirudinoidea), with a description of a new genus Motobdella, and species, M. sedonensis. Canadian Journal of Zoology 76: 1-9.

Govedich FR, Blinn DW, Hevly RH, Keim PS. 1999. Cryptic radiation in erpobdellid leeches in xeric landscapes: a molecular analysis of population differentiation. Canadian Journal of Zoology 77: 52-57.

Grosser C. 2004. Haemopis elegans (Hirudinea: Haemopidae) ein wiederentdecktes europäisches Egeltaxon. Lauterbornia 52: 77-86.

Grosser C. Egel Europas, available at www.http://freenethomepage.de/hirudinea. Updated 26.xi.2009.

Gustafsson DR, Price DA, Erséus C. 2009. Genetic variation in the popular lab worm Lumbriculus variegatus (Annelida: Clitellata: Lumbriculidae) reveals cryptic speciation. Molecular Phylogenetics and Evolution 51: 182-189.

Hebert PDN, Cywinska A, Shelley BL, de Waard JR. 2003. Biological identifications through DNA barcodes. Proceeding of the Royal Society London B. 270: 313-321.

Hermann PM, Genereux B, Wildering WC. 2009. Evidence for age-dependent mating strategies in the simultaneous hermaphrodite snail, Lymnaea stagnalis (L.). J. Experimental Biology 212: 3164-3173.

Hovingh P. 2004. Erpobdella (Dina) parva complex (Annelida: Hirudinea: Arhynchobdellida: Erpobdellidae): additional description of Erpobdella parva, E. dubia, and E. lahontana and taxonomic revision. Hydrobiologia 517: 89-105.

Hull SL. 1998. Assortative mating between two distinct microallopatric populations of Littorina saxatilis (Olivi) on the northeast coast of England. International Symposium on Littorinid Biology No5, Cork , Ireland, 378: 79-88.

International Code of Zoological Nomenclature. 1999. Available online at: http://www.nhm.ac.uk/hosted-sites/iczn/code/.

Jueg U, Grosser C, Bielecki A. 2004. Zur Kenntnis der Fischegelfauna (Hirudinea: Piscicolidae) in Deutschland. Lauterbornia 52: 39-73.

King JL, Hanner R. 1998. Cryptic species in a 'living fossil' lineage: taxonomic and phylogenetic relationships within the genus Lepidurus (Crustacea: Notostraca) in North America. Molecular Phylogenetics and Evolution 10: 23-36.

Koperski P. 2002. Factors determining diversity in diet composition: mutlivariate analysis of a guild of epiphytic predators. Archiv für Hydrobiologie 155: 291-314.

Koperski P. 2006. Relative importance of factors determining diversity and composition of freshwater leech assemblages (Hirudinea; Clitellata): a metaanalysis. Archiv für Hydrobiologie 166: 325-341.

Koperski P, Milanowski R, Krzyk A. 2008. Morphological, ecological and genetic divergence in populations of Erpobdella octoculata (Hirudinea). Lauterbornia 65: 63-67.

Korinkova T, Petrusek A, Jurickova L. 2006. Sphaerium corneum / nucleus (Bivalvia: Veneroida: Sphaeriidae) is a complex of several cryptic species. The Malacologist 48: 10.
Leidy J. 1868. Notice of some American leeches. Proceedings of the Academy Natural Sciences of Philadelphia 20: 229-230.

Linnaeus C. 1758. Systema naturae per regna tria naturae, secundum classes, ordines, genera, species, cum characteribus, differentiis, synonymis, locis. Tomus I. Editio decima, reformata. Holmiae. (Salvius).

Linnaeus C. 1761. Fauna Svecica sistens animalia Sveciæ Regni: mammalia, aves, amphibia, pisces, insecta, vermes. Distributa per classes \& ordines, genera \& species, cum differentiis specierum, synonymis auctorum, nominibus incolarum, locis natalium, descriptionibus insectorum. Editio altera, auctior. Stockholmiae. (L. Salvii).

Maltby L, Calow P. 1986. Intraspecific life-history variation in Erpobdella octoculata (Hirudinea: Erpobdellidae). I. Field study. Journal of Animal Ecology 55: 721-738.

Moore JP. 1912. Classification of the leeches of Minnesota. Part III. The leeches of Minnesota. Geological and Natural History Survey of Minnesota, Zoological series No. 5, Pt. 3: 63143.

Munday PL, van Herwerden L, Dudgeon CL. 2004. Evidence for sympatric speciation by host shift in the sea. Current Biology 14: 1498-1504.

Neubert E, Nesemann H. 1999. Annelida, Clitellata: Branchiobdellida, Acanthobdellea, Hirudinea. Süßwasserfauna von Mitteleuropa 6/2. Heidelberg: Spektrum.

Nilssen JP, Hobæk A, Petrusek A, Skage M. 2007. Restoring Daphnia lacustris G.O. Sars, 1862 (Crustacea, Anomopoda): a cryptic species in the Daphnia longispina group. Hydrobiologia 594: 5-17

Paredes-Esquivel C, Donnelly MJ, Harbach RE, Townson H. 2009. A molecular phylogeny of mosquitoes in the Anopheles barbirostris subgroup reveals cryptic species: Implications for identification of disease vectors. Molecular Phylogenetics and Evolution 50: 141-151.

Pawłowski LK. 1936. Hirudinea. Fauna Słodkowodna Polski, 26, Warszawa: Wydawnictwo Towarzystwa Wspierania Nauki, (in Polish).

Petrauskiene L, Utevska O, Utevski S. 2009. Can different species of medicinal leeches (Hirudo spp.) interbreed? Invertebrate Biology 128: 324-331.

Pfenninger M, Nowak C, Kley C, Steinke D, Streit B. 2007. Utility of DNA taxonomy and barcoding for the inference of larval community structure in morphologically cryptic Chironomus (Diptera) species. Molecula Ecology 16: 1957-1968.

Savigny J-C. 1822. Systemé de Annelides, principales de celles des côtes de l'Egypte et de la Syrie. Paris.

Schliewen UK, Kocher TD, McKaye KR, Seehausen O, Tautz D. 2006. Evolutionary Biology: Evidence for sympatric speciation? Nature 444: E12-E13, doi:10.1038/nature05419.

Suatoni E, Vicario S, Rice S, Snell T, Caccone A. 2006. An analysis of species boundaries and biogeographic patterns in a cryptic species complex: The rotifer-Brachionus plicatilis. Molecular Phylogenetics and Evolution 41: 86-98.

Trontelj P, Sket B. 2000. Molecular re-assessment of some phylogenetic, taxonomic and biogeographic relationships between the leech genera Dina and Trocheta (Hirudinea: Erpobdellidae). Hydrobiologia 438: 227-235.

Utevsky S, Trontelj P. 2004. Phylogenetic relationships of fish leeches (Hirudinea, Piscicolidae) based on mitochondrial DNA sequences and morphological data. Zoologica Scripta 33: 375-385. 
Verovnik R, Trontelj P, Sket B. 1999. Genetic differentiation and species status within the leech Glossiphonia complanata aggregate (Hirudinea: Glossiphonidae) revealed by RAPD analysis. Archiv für Hydrobiologie 144: 327-338.

Welsh J, McClelland M. 1990. Fingerprinting genomes using PCR with arbitrary primers. Nucleid Acids Research 18: 7213-7218.

Wen J, Zimmer EA. 1996. Phylogeny and biogeography of Pan$a x \mathrm{~L}$. (the ginseng genus, Araliaceae): inferences from ITS sequences of nuclear ribosomal DNA. Molecular Phylogenetics and Evolution 6: 167-177.

Williams HC, Ormerod SJ, Bruford MW. 2006. Molecular systematics and phylogeography of the cryptic species complex
Baetis rhodani (Ephemeroptera, Baetidae). Molecular Phylogenetics and Evolution 40: 370-382.

Zhou HT, Gao YY, Chen X, Ye F, Lian YW. 2005. Study on genetic diversity and resource conservation of amphioxus (Branchiostoma balcheri Gray) population. Acta Oceanologica Sinica 24: 102-112.

Received: 24 March 2010

Revised and accepted: 1 December 2010

Published online: 21 February 2011

Editor: M. Schilthuizen 

